\title{
Fast Synthesis of Multilayer Carbon Nanotubes from Camphor Oil as an Energy Storage Material
}

\author{
Amin TermehYousefi, ${ }^{1}$ Samira Bagheri, ${ }^{2}$ Kawasaki Shinji, ${ }^{3}$ \\ Jalal Rouhi, ${ }^{4}$ Mohamad Rusop Mahmood, ${ }^{4}$ and Shoichiro Ikeda ${ }^{1}$ \\ ${ }^{1}$ ChECA IKohza, Department of Environmental \& Green Technology (EGT), Malaysia Japan International Institute of \\ Technology (MJIIT), University Technology Malaysia (UTM), Kuala Lumpur, Malaysia \\ ${ }^{2}$ Nanotechnology \& Catalysis Research Centre (NANOCAT), IPS Building, University of Malaya, 50603 Kuala Lumpur, Malaysia \\ ${ }^{3}$ Nagoya Institute of Technology, Gokiso-Cho, Showa-Ku, Nagoya 466-8555, Japan \\ ${ }^{4}$ NANO-SciTech Centre, Institute of Science, Universiti Teknologi MARA (UiTM), Shah Alam, Selangor, Malaysia
}

Correspondence should be addressed to Samira Bagheri; samira_bagheri@um.edu.my

Received 18 June 2014; Revised 29 July 2014; Accepted 31 July 2014; Published 2 September 2014

Academic Editor: Meisam Tabatabaei

Copyright (C) 2014 Amin TermehYousefi et al. This is an open access article distributed under the Creative Commons Attribution License, which permits unrestricted use, distribution, and reproduction in any medium, provided the original work is properly cited.

\begin{abstract}
Among the wide range of renewable energy sources, the ever-increasing demand for electricity storage represents an emerging challenge. Utilizing carbon nanotubes (CNTs) for energy storage is closely being scrutinized due to the promising performance on top of their extraordinary features. In this work, well-aligned multilayer carbon nanotubes were successfully synthesized on a porous silicon (PSi) substrate in a fast process using renewable natural essential oil via chemical vapor deposition (CVD). Considering the influx of vaporized multilayer vertical carbon nanotubes (MVCNTs) to the PSi, the diameter distribution increased as the flow rate decreased in the reactor. Raman spectroscopy results indicated that the crystalline quality of the carbon nanotubes structure exhibits no major variation despite changes in the flow rate. Fourier transform infrared (FT-IR) spectra confirmed the hexagonal structure of the carbon nanotubes because of the presence of a peak corresponding to the carbon double bond. Field emission scanning electron microscopy (FESEM) images showed multilayer nanotubes, each with different diameters with long and straight multiwall tubes. Moreover, the temperature programmed desorption (TPD) method has been used to analyze the hydrogen storage properties of MVCNTs, which indicates that hydrogen adsorption sites exist on the synthesized multilayer CNTs.
\end{abstract}

\section{Introduction}

Research and development of energy in the 21st century focused on a wide range of renewable energy sources, due to concerns over fossil fuel and its ever-aggravating impact on global warming, environments, and the crisis of natural resource depletion $[1,2]$. Carbon nanotubes have gained significant research interest for their potential applications, such as generating electricity [3] and electricity storage [4], that is, the administrable ability to capture, store, and deliver generated power. The properties of CNTs depend on the arrangement of their graphitic rings and the diameter of their helical structure [5].

CVD is a common CNTs synthesis method based on thermal decomposition of hydrocarbon vapors [6].
The properties of CNTs depend not only on the deposition condition but the starting precursor as well [7]. For various kinds of the deposition process, graphite target is commonly used for the preparation of carbon-based materials [8]. Natural essential oils, a major source of renewable energy, are regarded as promising to the world's thirst for energy $[9,10]$. Camphor oil is found in wood of the camphor laurel (Cinnamomum camphora), which is a large evergreen tree found in Asia, Dryobalanops aromatica, a giant of the Bornean forests, and some other related trees in the laurel family, notably Ocotea usambarensis. Camphor readily ignites and burns without producing any residue. However, camphor $\left(\mathrm{C}_{10} \mathrm{H}_{16} \mathrm{O}\right)$, which consists of both $\mathrm{sp}^{2}$ and $\mathrm{sp}^{3}$ carbons, is an attractive new material for carbon-based preparation, since graphite has only $\mathrm{sp}^{2}$ carbon [11]. 
The petroleum-based precursors for synthesis of CNTs have been investigated in detail, and the easy availability of high-grade precursors has resulted in the production and process optimization of different types, structure, dimension, and orientations of CNTs. However, the naturally occurring hydrocarbon precursors have generated some interest because of the possibility of production of CNTs from the bank of hydrocarbons that are being renewably produced by nature in a carbon-neutral manner [12]. So, it becomes important to search for new natural renewable precursors that are easily available and are low in cost, such as essential oils. Of course, it calls for studies that are related to yield and quality of the CNTs being produced and the applications of the resultant CNTs.

Grown MVCNTs arrays with different diameter distribution feeding gas velocity ( $\mathrm{sccm}$ ) have significant effects on CNTs, especially on their diameter distribution [13]. To date, the cause of diameter alterations in single CNTs structures has yet to be clearly understood [14]. Heterostructured multilayer CNTs are fabricated via conventional methods separated by continuous steps, which may be repeated to provide three or more layers of CNTs [15]. Various catalyst formulations and reaction conditions have also been developed to enable the formation of multiple layers of CNTs through the use of appropriate catalysts for different layers [16]. Obtaining a comprehensive understanding of the CNTs growth mechanism is necessary to achieve better control of CNTs growth and design possible nanostructures [17].

Several researchers have reported different types of CNTs based on variations in the parameters in multiple processes [18]; however, to the best of our knowledge, the single step developed in this study is a new method that allows for the control of the diameter of CNTs on PSi. In the present study, MVCNTs were successfully synthesized on a PSi substrate in a one-step process using renewable natural camphor oil via CVD. Moreover, the diameter of CNTs produced through the optimized growth condition is limited by controlling the diffusion of feedstock and also hydrogen storage characteristic of the synthesized multilayer CNTs being analyzed.

\section{Experimental Procedure}

The experimental setup is based on horizontal electronic furnaces used to cover the quartz tube during CNTs fabrication. A mass flow controller was used to adjust the velocity of the carrier gas by means of syringe pump into Psi, which was fabricated via selective doping [19].

Camphor oil as a precursor was mixed with ferrocene and then introduced to the inlet of the quartz tube fitted by the first furnace to release the vaporized CNTs. The reaction temperature was increased to $180^{\circ} \mathrm{C}$ and maintained for $30 \mathrm{~min}$ to ensure that the precursor and catalysts were completely pyrolyzed. Ferrocene decomposes to form the iron catalyst necessary for the experiment, while camphor acts as a carbon source (feedstock) of the substrate in the second furnace. The CVD experiments commenced when the deposition temperature of the second furnace reached the optimal temperature (between 750 and $850^{\circ} \mathrm{C}$ ). The exhaust argon gas in the quartz tube induced movement of the amorphous vaporized carbon into the second furnace by means of a mass flow controller, thereby allowing CNTs growth on the surface of the proposed substrate [20]. To identify the relation between the flow rate and CNTs diameter on the substrate, three flow rates were employed at 1 bar. Argon gas was injected into the inlet of the quartz tube at a maximum velocity of $600 \mathrm{sccm}$. After $10 \mathrm{~min}$, the velocity was gradually decreased to $400 \mathrm{sccm}$ as its median range of the flow rate. Then, after $20 \mathrm{~min}$, the flow rate was decreased to $200 \mathrm{sccm}$ until complete consumption of the carbon source. After $1 \mathrm{~h}$ of reaction time, the reactor was cooled down slowly to room temperature in Ar ambient space after the synthesis.

The CNTs were characterized by FESEM (ZEISS Supra $40 \mathrm{VP}$ ) operated at $5 \mathrm{kV}$ to evaluate the structure and diameter of the samples. Raman spectra were obtained using microRaman spectroscopy (Horiba Jobin Yvon-DU420A-OE-325), with $\mathrm{Ar}^{+}$ions at $514.5 \mathrm{~nm}$ to determine the adsorption, desorption, and surface area of the samples. The surface structure of the CNTs was confirmed by a VECTOR33 FTIR instrument. The chemisorption analyses of the synthesized CNTs were done by TPDRO 1100.

During the TPD analysis, the sample, adequately pretreated, is submitted at an increasing temperature at a constant rate and is swept by an inert gas such as helium. The sample surface desorbs the gas that has been previously chemisorbed, and a suitable detector monitors the process. In the TPD studies, the solid system is previously equilibrated until saturation, with a probe gas in isothermal conditions at a given partial pressure [21].

\section{Results and Discussion}

As shown in Figure 1, vertically-aligned CNTs with high uniformity and nearly identical diameters were fabricated. FESEM images confirm that well-aligned CNTs with three different diameters were synthesized. As the flow rate decreases, the CNTs gradually thicken [22]. The duration of carrier gas feeding and its flow rate into the reaction zone are key parameters controlling the CNTs diameter [18]. The growth rates of the active ends of the CNTs vary proportionally to the flow rate of argon gas until complete consumption of the carbon source [23]. Alteration of the flow velocity during deposition and limited gas-flow rate control the growth conditions of the CNTs [24].

Considering the influx of vaporized CNTs to the PSi, the diameter distribution increases as the flow rate decreased in the reactor. The quantity of carbons covalently attached to the active end of the tube increased with decreasing flow rates [25]. Various diameters of CNTs are evident during structural transition of the feedstock around the substrate. During the first stage of the experiment, the average diameter of the tubes is approximately $30 \mathrm{~nm}$, and high uniformity is observed. Reducing the flow rate during deposition process changes the diameters of the tubes and produces a central layer with uniformity that is identical to that in the first layer, with an average diameter of $75 \mathrm{~nm}$. The minimum flow rate generates the last layer of multilayer CNTs with the different geometry 


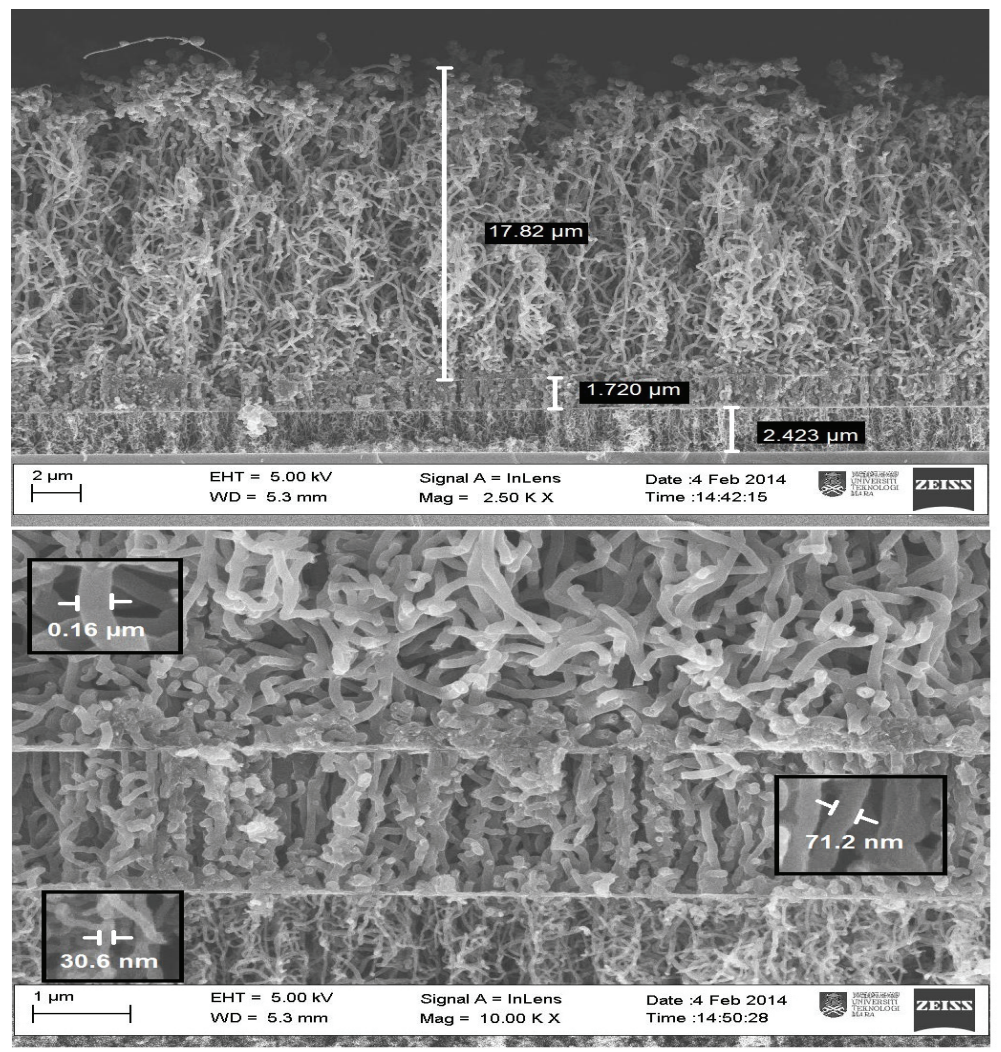

FIGURE 1: FESEM images of the heterostructured fast synthesized multilayer carbon nanotubes.

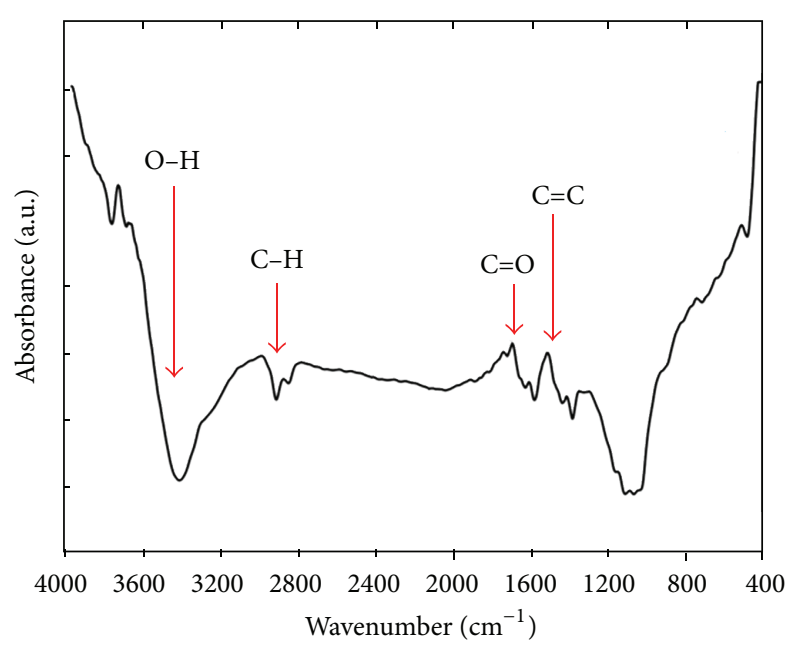

FIGURE 2: FT-IR spectrum of the fast synthesized multilayer carbon nanotubes.

as the previous layers and average diameter to up to $1 \mu \mathrm{m}$; this final layer is obtained by terminating the carbon source.

FESEM images show that variations in flow rate could systematically change the diameter distribution of the CNTs. We propose that at any given flow rate an optimal diameter exists for the CNTs. Varying the carrier gas flow rate during the growth process can be employed to control the growth of CNTs [13].
TABLE 1: FT-IR spectroscopy absorption bands of multilayer carbon nanotubes.

\begin{tabular}{lc}
\hline Frequency $\left(\mathrm{cm}^{-1}\right)$ & Possible assignment \\
\hline 3424 & H-bonded OH groups \\
2928 & C-H bending, stretching \\
1699 & C=O stretching \\
1540 & C=C stretching \\
\hline
\end{tabular}

Given that other parameters, such as carbon feeding rate, temperature, and type of carrier gas, can be altered during CNTs synthesis, our hypothesis also can be developed due to alteration of the other parameters involved with growth process such as multilayer growth of CNTs dependence on temperature [26]. At low temperatures, only small nanoparticles are activated; altering the temperature parallel to the flow rate can change the growth efficiency and aspect ratio of the CNTs [25].

The FT-IR spectrum $\left(400 \mathrm{~cm}^{-1}\right.$ to $\left.4000 \mathrm{~cm}^{-1}\right)$ of the fabricated CNTs is shown in Figure 2, and the related peaks are summarized in Table 1. The spectra were recorded using pressed disks of the pure solid powders combined with $\mathrm{KBr}$. Only a small C-C stretch and a peak at $1532 \mathrm{~cm}^{-1}$ to $1560 \mathrm{~cm}^{-1}$ were observed, which indicates the presence of a carbon double bond $(\mathrm{C}=\mathrm{C})$; this finding confirms the hexagonal structure of the CNTs [27]. Figure 3 shows the Raman spectra of the CNTs. 


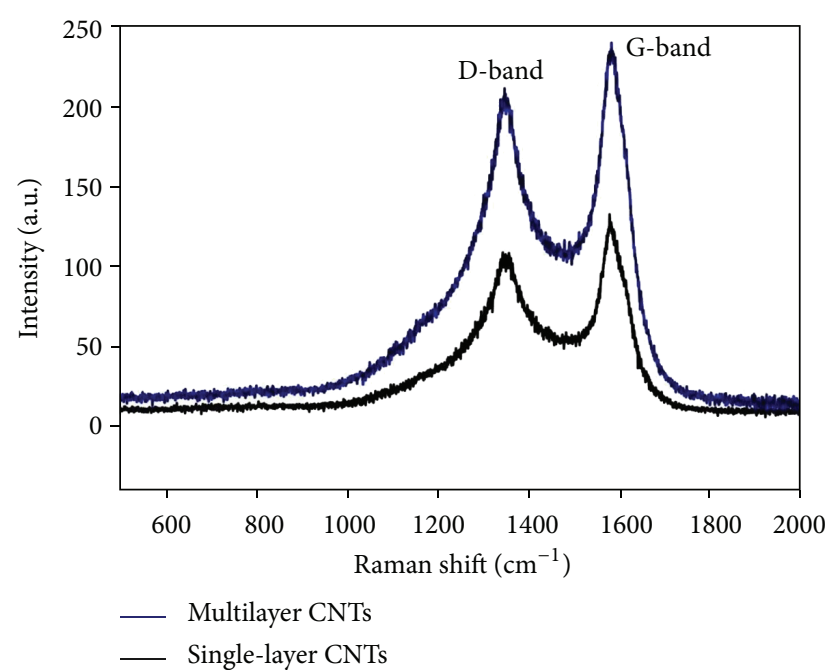

FIGURE 3: Raman spectra of the fast synthesized multilayer carbon nanotubes.

The Raman results have been compared with the growth CNTs in a unique flow rate to ensure the effect of the transitive gas flow on the growth process. Accordingly, two main peaks are found at $1348 \mathrm{~cm}^{-1}$ and $1577 \mathrm{~cm}^{-1}$; these peaks correspond to the $D$ and $G$ bands, respectively [28]. The $I_{D} / I_{G}$ ratio suggests that the crystallinity of the synthesized CNTs under varying flow rates is identical to those grown under a fixed flow rate [29]. The $I_{D} / I_{G}$ ratio for both types of CNTs is approximately 1.12. As such, the crystalline quality of the CNTs shows no major variation despite changes in flow rate [30].

The growth carbon nanotubes might be a suitable nanostructure for hydrogen storage devices, since for multiwall carbon nanotubes the hydrogen storage capacity is independent of tube's diameter [31]. Furthermore, there are also repulsive forces present between the $\mathrm{H}$ and $\mathrm{C}$ atoms. This energy tends to become larger as the diameter of tube increases. The potential of nanostructured materials is not only limited to energy storage and conversion devices but also to nanotransistors [32], actuators [33], electron field emission [34], and biological sensing devices [35].

The hydrogen adsorption properties of the fast synthesized multilayer CNTs were explored in Figure 4. Accordingly, the sample was degassed to $100^{\circ} \mathrm{C}$ and exposed to hydrogen at 760 Torr to obtain a TPD spectrum. For comparison, a TDP spectrum of a single layer CNTs also was degassed in the same condition, which was shown in the inset in Figure 4. In both cases, the sample was cooled to $\sim 190 \mathrm{~K}$, while the $\mathrm{H}_{2}$ gas was evacuated [36]. These results indicate that unique hydrogen adsorption sites exist on the fast synthesized multilayer CNTs and display a hydrogen adsorption capacity at near ambient conditions that is $\sim 2 \mathrm{x}$ greater than that of single layer CNTs. Therefore, conclusively, it can be concluded that multilayer CNTs may also be promising candidates for vehicular hydrogen storage applications [37].

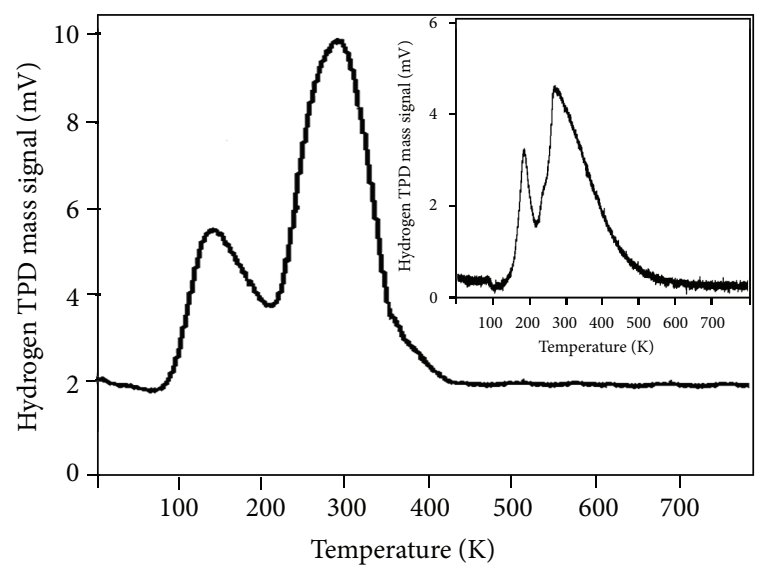

FIGURE 4: Hydrogen TPD spectra of the fast synthesized multilayer carbon nanotubes. Inset figure represents hydrogen TPD spectra of single layer carbon nanotubes.

\section{Conclusion}

Well-aligned CNTs with three different diameters have been synthesized by employing different flow rates. FESEM images show that varying the flow rate could systematically change the diameter distribution of the CNTs. Reducing the flow rate during deposition process changes the diameter of the tubes, thereby producing a central layer of CNTs with the same uniformity as that in the first layer. The minimum flow rate generates the last layer of the CNTs structure with the same geometry as the previous layers and high average diameter. FT-IR spectrum indicates the presence of carbon double bonds $(\mathrm{C}=\mathrm{C})$, which confirms the integrity of the hexagonal structure of the CNTs. The obtained Raman spectra indicate that the crystallinity of the CNTs structure exhibits no major variation despite changes in flow rate. According to the TPD method for the hydrogen storage properties of MVCNTs, the fast synthesized multilayer CNTs for the hydrogen adsorption capacity at near ambient conditions are $\sim 2 \mathrm{x}$ greater than the single-layer CNTs. These results demonstrate a new geometric combination of CNTs based on heterostructured multilayer nanotubes, which can be used in energy storage devices because of their nanosize distribution of carbon nanotubes, accessible surface area, and high stability.

\section{Conflict of Interests}

The authors declare that they have no conflict of interests.

\section{Acknowledgments}

This work was supported by the University Malaya Research Grant (BK018-2014) and High Impact Research Grant UM.C/HIR/MOHE/ENG/44 from the Ministry of Higher Education (MOHE), Malaysia. 


\section{References}

[1] Z. Cao and B. B. Wei, "A perspective: carbon nanotube macrofilms for energy storage," Energy Environmental Science, vol. 6, no. 11, pp. 3183-3201, 2013.

[2] J. Sundaramurthy, N. Li, P. S. Kumar, and S. Ramakrishna, "Perspective of electrospun nanofibers in energy and environment," Biofuel Research Journal, vol. 1, no. 2, pp. 44-54, 2014.

[3] B. J. LeRoy, S. G. Lemay, J. Kong, and C. Dekker, "Electrical generation and absorption of phonons in carbon nanotubes," Nature, vol. 432, no. 7015, pp. 371-374, 2004.

[4] A. S. Aricò, P. Bruce, B. Scrosati, J.-M. Tarascon, and W. Van Schalkwijk, "Nanostructured materials for advanced energy conversion and storage devices," Nature Materials, vol. 4, no. 5, pp. 366-377, 2005.

[5] M. Liu and J. M. Cowley, "Structures of the helical carbon nanotubes," Carbon, vol. 32, no. 3, pp. 393-403, 1994.

[6] C. J. Lee, D. W. Kim, T. J. Lee et al., "Synthesis of aligned carbon nanotubes using thermal chemical vapor deposition," Chemical Physics Letters, vol. 312, no. 5-6, pp. 461-468, 1999.

[7] Y. Chen, C. Gan, T. Zhang, G. Yu, P. Bai, and A. Kaplan, "Lasersurface-alloyed carbon nanotubes reinforced hydroxyapatite composite coatings," Applied Physics Letters, vol. 86, no. 25, Article ID 251905, pp. 1-3, 2005.

[8] K. Koziol, B. O. Boskovic, and N. Yahya, "Synthesis of carbon nanostructures by CVD method," Advanced Structured Materials, vol. 5, pp. 23-49, 2011.

[9] S. R. Bull, "Renewable energy today and tomorrow," Proceedings of the IEEE, vol. 89, no. 8, pp. 1216-1226, 2001.

[10] M. Akia, F. Yazdani, E. Motaee et al., "A review on conversion of biomass to biofuel by nanocatalysts," Biofuel Research Journal, vol. 1, no. 1, pp. 16-25, 2014.

[11] G. Kasiraman, B. Nagalingam, and M. Balakrishnan, "Performance, emission and combustion improvements in a direct injection diesel engine using cashew nut shell oil as fuel with camphor oil blending," Energy, vol. 47, no. 1, pp. 116-124, 2012.

[12] Z. Sadeghian, "Large-scale production of multi-walled carbon nanotubes by low-cost spray pyrolysis of hexane," New Carbon Materials, vol. 24, no. 1, pp. 33-38, 2009.

[13] C.-S. Kuo, A. Bai, C.-M. Huang, Y.-Y. Li, C.-C. Hu, and C.C. Chen, "Diameter control of multiwalled carbon nanotubes using experimental strategies," Carbon, vol. 43, no. 13, pp. 2760 2768, 2005.

[14] A. T. Yousefi, S. Ikeda, M. R. Mahmood et al., "Simulation of nano sensor based on carbon nanostructures in order to form multifunctional delivery platforms," Advanced Materials Research, vol. 832, pp. 778-782, 2014.

[15] L. Dai and S. Huang, "Multilayer carbon nanotube films and method of making the same," Google Patents, 2004 .

[16] A. M. Cassell, M. Meyyappan, and J. Han, "Multilayer film assembly of carbon nanotubes," Journal of Nanoparticle Research, vol. 2, no. 4, pp. 387-389, 2000.

[17] Q. Zhang, J. Q. Huang, M. Q. Zhao, W. Z. Qian, Y. Wang, and F. Wei, "Radial growth of vertically aligned carbon nanotube arrays from ethylene on ceramic spheres," Carbon, vol. 46, no. 8, pp. 1152-1158, 2008.

[18] C. Singh, M. S. P. Shaffer, and A. H. Windle, "Production of controlled architectures of aligned carbon nanotubes by an injection chemical vapour deposition method," Carbon, vol. 41, no. 2, pp. 359-368, 2003.
[19] T. E. Bell, P. T. J. Gennissen, D. Demunter, and M. Kuhl, "Porous silicon as a sacrificial material," Journal of Micromechanics and Microengineering, vol. 6, no. 4, pp. 361-369, 1996.

[20] Y. Hao, Z. Qunfeng, W. Fei, Q. Weizhong, and L. Guohua, "Agglomerated CNTs synthesized in a fluidized bed reactor: agglomerate structure and formation mechanism," Carbon, vol. 41, no. 14, pp. 2855-2863, 2003.

[21] M. Fadoni and L. Lucarelli, "Temperature programmed desorption, reduction, oxidation and flow chemisorption for the characterisation of heterogeneous catalysts. Theoretical aspects, instrumentation and applications," in Studies in Surface Science and Catalysis, A. Dąbrowski, Ed., pp. 177-225, Elsevier, 1999.

[22] A. G. Kurenya, D. V. Gorodetskiy, V. E. Arkhipov, and A. V. Okotrub, "Evaluation of the optimal carrier gas flow rate for the carbon nanotubes growth," Technical Physics Letters, vol. 39, no. 3, pp. 258-261, 2013.

[23] M. Kumar and Y. Ando, "Chemical vapor deposition of carbon nanotubes: a review on growth mechanism and mass production," Journal of Nanoscience and Nanotechnology, vol. 10, no. 6, pp. 3739-3758, 2010.

[24] C. Lu and J. Liu, "Controlling the diameter of carbon nanotubes in chemical vapor deposition method by carbon feeding," Journal of Physical Chemistry B, vol. 110, no. 41, pp. 20254-20257, 2006.

[25] C. J. Lee, S. C. Lyu, Y. R. Cho, J. H. Lee, and K. I. Cho, "Diametercontrolled growth of carbon nanotubes using thermal chemical vapor deposition," Chemical Physics Letters, vol. 341, no. 3-4, pp. 245-249, 2001.

[26] C. J. Lee, J. Park, Y. Huh, and J. Yong Lee, “Temperature effect on the growth of carbon nanotubes using thermal chemical vapor deposition," Chemical Physics Letters, vol. 343, no. 1-2, pp. 33-38, 2001.

[27] R. Yudianti, H. Onggo, Y. Saito, T. Iwata, and J.-I. Azuma, "Analysis of functional group sited on multi-wall carbon Nanotube surface," Open Materials Science Journal, vol. 5, pp. 242-247, 2011.

[28] Y. Yadav, V. Kunduru, and S. Prasad, "Carbon nanotubes: synthesis and characterization," in Nanopackaging, pp. 325-344, Springer, 2008.

[29] R. A. DiLeo, B. J. Landi, and R. P. Raffaelle, "Purity assessment of multiwalled carbon nanotubes by Raman spectroscopy," Journal of Applied Physics, vol. 101, no. 6, Article ID 064307, 2007.

[30] C. Vallés, M. Pérez-Mendoza, W. K. Maser et al., "Effects of partial and total methane flows on the yield and structural characteristics of MWCNTs produced by CVD," Carbon, vol. 47, no. 4, pp. 998-1004, 2009.

[31] S. M. Lee and Y. H. Lee, "Hydrogen storage in single-walled carbon nanotubes," Applied Physics Letters, vol. 76, no. 20, pp. 2877-2879, 2000.

[32] W. B. Choi, J. U. Chu, K. S. Jeong et al., "Ultrahigh-density nanotransistors by using selectively grown vertical carbon nanotubes," Applied Physics Letters, vol. 79, no. 22, pp. 36963698, 2001.

[33] I. Chen, Z. Liang, B. Wang, and C. Zhang, "Charge-induced asymmetrical displacement of an aligned carbon nanotube buckypaper actuator," Carbon, vol. 48, no. 4, pp. 1064-1069, 2010.

[34] W. A. de Heer, A. Châtelain, and D. Ugarte, "A carbon nanotube field-emission electron source," Science, vol. 270, no. 5239, pp. 1179-1180, 1995. 
[35] F. Chekin, S. Bagheri, and S. A. Hamid, "Electrochemistry and electrocatalysis of cobalt(II) immobilized onto gel-assisted synthesized zinc oxide nanoparticle-multi wall carbon nanotubepolycaprolactone composite film: application to determination of glucose," Analytical Methods, vol. 4, no. 8, pp. 2423-2428, 2012.

[36] A. C. Dillon, K. E. H. Gilbert, P.A. Parilla et al., "Hydrogen storage in carbon single-wall nanotubes," in Proceedings of the US DOE Hydrogen Program Review, 2002.

[37] A. Züttel, P. Sudan, P. Mauron, T. Kiyobayashi, C. Emmenegger, and L. Schlapbach, "Hydrogen storage in carbon nanostructures," International Journal of Hydrogen Energy, vol. 27, no. 2, pp. 203-212, 2002. 

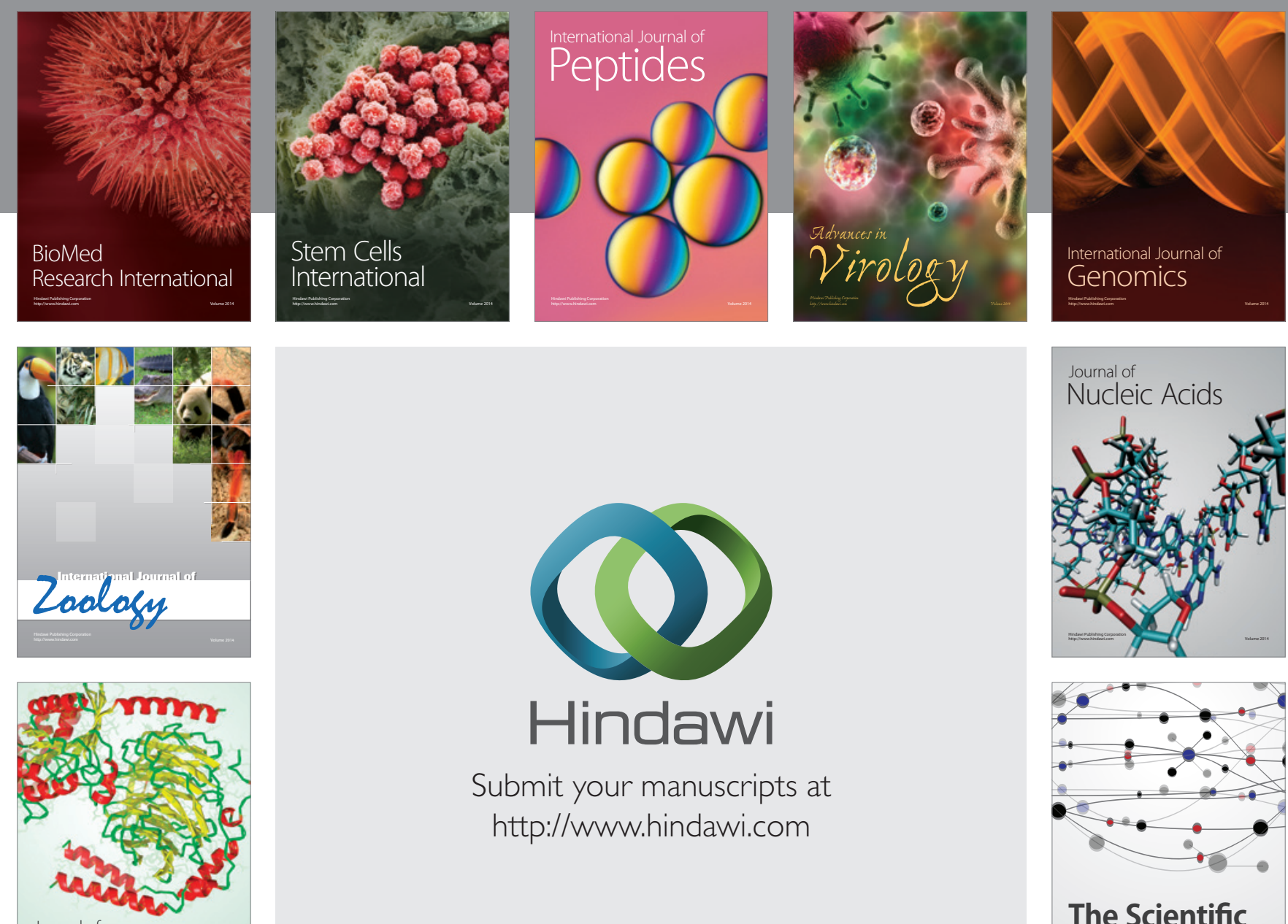

Submit your manuscripts at

http://www.hindawi.com

Journal of
Signal Transduction
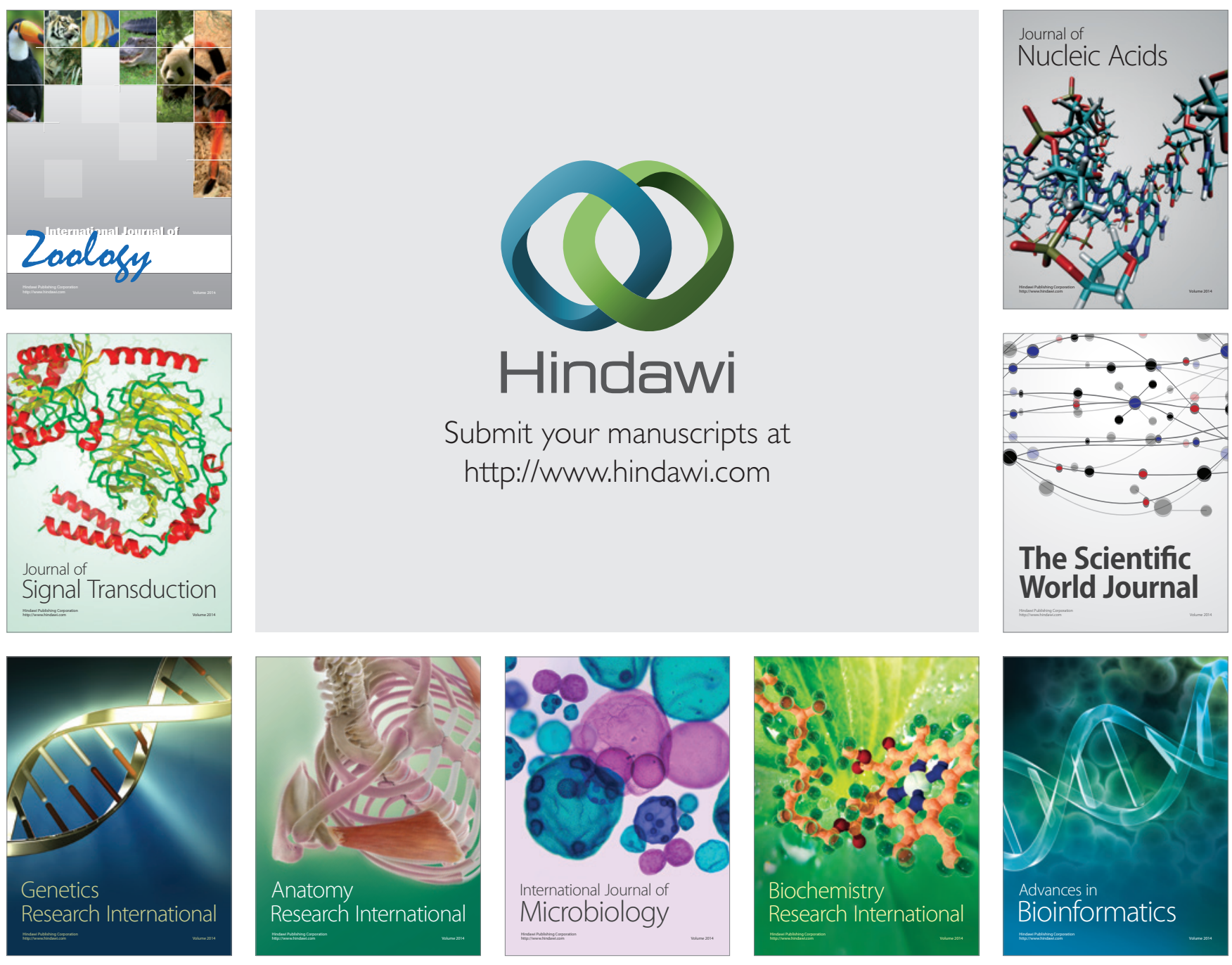

The Scientific World Journal
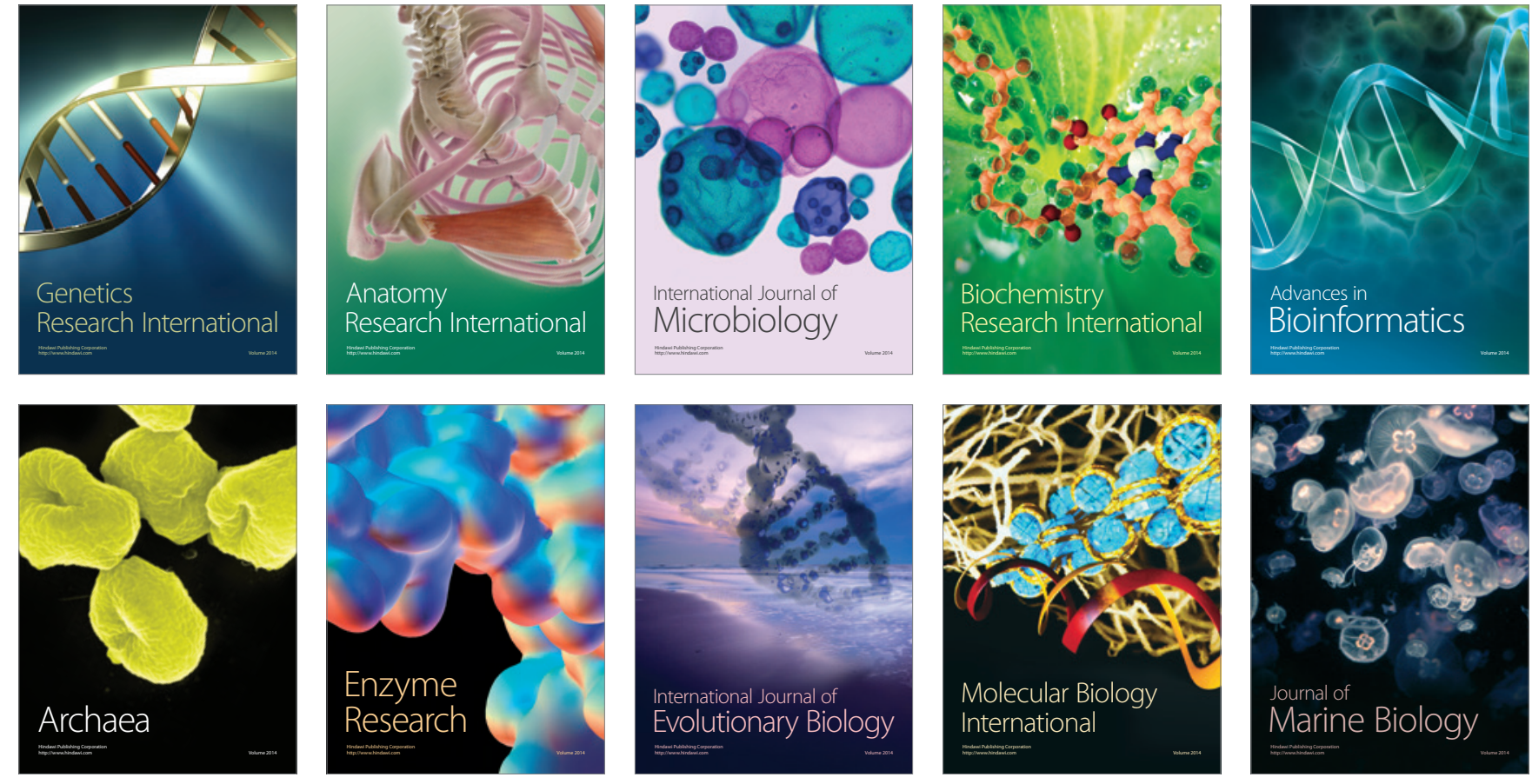